\title{
Hubungan Ukuran Butir Terhadap Suseptibilitas Magnetik dan Kandungan Unsur Mineral Magnetik Pasir Besi Pantai Sunur Kabupaten Padang Pariaman
}

\author{
Frizky Norman, Arif Budiman, Dwi Puryanti \\ Jurusan Fisika Universitas Andalas, Kampus Limau Manis Padang, 25163 \\ *normanfrizky888@gmail.com
}

\begin{abstract}
ABSTRAK
Telah dilakukan penelitian tentang hubungan ukuran butir terhadapsuseptibilitas magnetik dan kandungan unsur mineral magnetik pasir besi yang berasal dari Pantai Sunur Kabupaten Padang Pariaman. Pasir besi dikelompokkan menjadi lima kelompok yaitu ukuran butir > 0,850 mm (Kelompok I), 0,425 mm < ukuran butir $\leq 0,850 \mathrm{~mm}$ (Kelompok II), 0,180 $\mathrm{mm}<$ ukuran butir $\leq 0,425 \mathrm{~mm}$ (Kelompok III), 0,150 $\mathrm{mm}<$ ukuran butir $\leq 0,180 \mathrm{~mm}$ (Kelompok IV) dan ukuran butir $\leq 0,150 \mathrm{~mm}$ (Kelompok V). Pasir besi dipisahkan menggunakan ayakan ASTM sieve series. Pengukuran suseptibilitas magnetik menggunakan Bartington MS2 Magnetic susceptibility meter. Penentuan kandungan unsur mineral magnetik menggunakan X-Rays Flourescence (XRF).Hasil Penelitian menunjukkan pasir besi di Pantai Sunur Kabupaten Padang Pariaman didominasi oleh Kelompok II dan Kelompok III dengan ukuran butiran antara 0,180 - 0,850 mm.Persentase kandungan mineral magnetik tertinggi didapatkan pada Kelompok V yaitu sekitar 90,7 - 93,5\%. Kelompok V juga memiliki nilai suseptibilitas rata-rata tertinggi yaitu berkisar antara 4888,0 - 5512,8 $\times 10^{-8} \mathrm{~m}^{3} / \mathrm{kg}$. Hal ini disebabkan Kelompok V memiliki konsentrasi unsur Fe dan Ti tertinggi dan unsur Si terendah yaitu berturut-turut 42,9\%, 6,2 \% dan 34,5\%.

Kata kunci: Pantai Sunur, suseptibilitas magnetik, ukuran butir pasir besi
\end{abstract}

\section{ABSTRACT}

The relationship between grain size of iron sand and the magnetic susceptibility and element content of magnetic mineral has been revisited. The iron sand is from Sunur Beach in Padang Pariaman. The grain sizes were classified into five groups, i.e., grain size >0.850 mm (Group I), $0.425 \mathrm{~mm}<$ grain size $\leq$ $0.850 \mathrm{~mm}$ (Group II), $(0.180 \mathrm{~mm}<$ grain size $\leq 0.425 \mathrm{~mm}$ ) (Group III), $0.150 \mathrm{~mm}<$ grain size $\leq 0.180$ $\mathrm{mm}($ Group IV) and grain size $\leq 0.150 \mathrm{~mm}$ (Group V). The iron sand was separated by using the ASTM sieve series. Furthermore, magnetic susceptibility was measured by using the Bartington MS2 Magnetic Susceptibility meter. Finally, the content of magnetic mineral was analyzed by X-Rays Flourescence $(X R F)$. It was found that the iron sand on Sunur Beach was dominated by Group II and III with the size of $0.180-0.850 \mathrm{~mm}$. The highest percentage of magnetic mineral wasabout $90.7-93.5 \%$, and it was observed for the Group V. The Group V had also the highest magnetic susceptibility with the value of $4888.0-5512.8 \times 10^{-8} \mathrm{~m}^{3} / \mathrm{kg}$. This result is consistent with the concentration of magnetic mineral element in which Fe and Ti are the highest concentration elements and Si was the lowest one. The concentration for such elements are $42.9 \%$ and $6.2 \%$ and $34.5 \%$, respectively.

Keywords:Sunur Beach, magnetic susceptibility, grain size iron sand

\section{PENDAHULUAN}

Mineral magnetik alam banyak terdapat di Indonesia dan diantaranya terdapat pada pasir besi. Pasir besi memiliki kandungan mineral magnetik yang digunakan pada produk industri seperti besi baja, tinta, pewarna (Yulianto, dkk., 2003), logam titanium (Zulfalina dan Manaf, 2004), media rekam magnetik (Yamamoto, dkk., 2001 dalam Yulianto dan Aji, 2010) dan material feroelektrik (Widanarto, dkk., 2013 dalam Jalil, dkk., 2014).

Agar bisa digunakan secara efisien dan ekonomis, maka dibutuhkan kajian tentang mineral magnetik pasir besi. Kajian tersebut meliputi analisis kimia dan analisis fisika. Analisis kimia bertujuan untuk mengetahui kandungan unsur pada mineral magnetik dan analisis fisika meliputi analisis jenis mineral, analisis ukuran butir, analisis sifat magnetik dan analisis berat jenis (Direktorat Inventarisasi Sumberdaya Mineral, 2005).

Pasir besi memiliki ukuran butir yang bervariasi dengan ukuran kasar (antara 3 hingga 5 $\mathrm{mm}$ ) dan ukuran halus (kecil dari $1 \mathrm{~mm}$ ) (Sunaryo dan Widiawidura, 2010). Kandungan mineral magnetik bergantung kepada ukuran butir. Semakin halus ukuran butir, maka kandungan mineral magnetiknya semakin tinggi (Suratman, 2008 dalam Ansori, 2013). Ketika ukuran butir memiliki hubungan terhadap kandungan mineral magnetik, maka sifat magnetik 
juga memiliki hubungan terhadap ukuran butir. Hal ini dikarenakan sifat magnetik suatu bahan dipengaruhi oleh kandungan mineral magnetik (Mufit, dkk., 2013).

Kandungan mineral magnetik pasir besi di Pantai Sunur Kabupaten Padang Pariaman didominasi oleh mineral magnetit $\left(\mathrm{Fe}_{3} \mathrm{O}_{4}\right)$, hematit $\left(\alpha-\mathrm{Fe}_{2} \mathrm{O}_{3}\right)$ dan ilmenit $\left(\mathrm{FeTiO}_{3}\right)($ Mufit, dkk., 2006). Penelitian tentang hubungan ukuran butir pasir besi terhadap kandungan mineral magnetik dan sifat magnetik di daerah tersebut belum pernah dilakukan. Oleh karena itu, telah dilakukan penelitian untuk mengetahui hubungan ukuran butir pasir besi di Pantai Sunur terhadap kandungan unsur mineral magnetik dan suseptibilitas magnetik. Hasil penelitian ini diharapkan memberikan informasi tentang potensi pemanfaatan pasir besi di Pantai Sunur.

\section{METODE}

\subsection{Pengambilan dan Pengeringan Sampel}

Pasir besi berasal dari tiga lokasi berbeda di Pantai Sunur Kabupaten Padang Pariaman (Tabel 1). Sampel pasir besi diambil sebanyak $500 \mathrm{~g}$ pada masing-masing lokasi, kemudian dikeringkan di bawah sinar matahari selama 24 jam untuk menghilangkan kandungan uap air.

Tabel 1 Koordinat lokasi sampel

\begin{tabular}{ccc}
\hline Lokasi Sampel & Bujur Timur & Lintang Selatan \\
\hline S1 & 99,25356 & 0,628904 \\
S2 & 99,25416 & 0,628848 \\
S3 & 99,25371 & 0,628889 \\
\hline
\end{tabular}

\subsection{Pemisahan Massa Pasir Besi Berdasarkan Ukuran Butir}

Pemisahan pasir besi dilakukan sebanyak 5 kali pengukuran menggunakan Sieve Shaker selama 15 menit untuk masing-masing sebesar $100 \mathrm{~g}$. Sampel pasir besi dipisahkan menjadi 5 kelompok menggunakan ayakan 20 Mesh, 40 Mesh, 80 Mesh dan 100 Mesh. Pengelompokkan pasir besi adalah sebagai berikut:

1. $\quad+20$ Mesh (Kelompok I)

Sampel pada kelompok ini merupakan pasir besi yang tertahan pada ayakan 20 Mesh. Sampel memiliki ukuran butir besar dari $0,850 \mathrm{~mm}$.

2. $-20+40$ Mesh (Kelompok II)

Sampel pada kelompok ini merupakan pasir besi yang tertahan pada ayakan 40 Mesh dan lolos tersaring pada ayakan 20 Mesh. Sampel memiliki ukuran butir antara 0,425 mm dan $0,850 \mathrm{~mm}$.

3. $-40+80$ Mesh (Kelompok III)

Sampel pada kelompok ini merupakan pasir besi yang tertahan pada ayakan 80 Mesh dan lolos tersaring pada ayakan 40 Mesh. Sampel memiliki ukuran butir antara 0,180 dan 0,425 $\mathrm{mm}$.

4. $-80+100$ Mesh (Kelompok IV)

Sampel pada kelompok ini merupakan pasir besi yang tertahan pada ayakan 100 Mesh dan lolos tersaring pada ayakan 80 Mesh.Sampel memiliki ukuran butir antara 0,150 dan 0,180 $\mathrm{mm}$.

5. -100 Mesh (Kelompok V)

Sampel pada kelompok ini merupakan pasir besi yang lolos tersaring pada ayakan 100 Mesh.Sampel memiliki ukuran butir kecil dari 0,150 mm.

\subsection{Penentuan Persentase Massa Kandungan Mineral Magnetik}

Sampel pasir besi pada masing-masing ukuran butir ditimbang massanya. Pasir besi dipisahkan secara manual menggunakan magnet permanen. Mineral yang menempel pada magnet permanen merupakan mineral magnetik, sedangkan mineral yang tidak menempel merupakan mineral non-magnetik. Perhitungan persentase massa kandungan mineral magnetik menggunakan persamaan:

$$
\operatorname{MM}(\%)=\frac{\text { massa mineral magnetik }}{\text { massa total pasir besi }} \times 100 \%
$$




\subsection{Penentuan Nilai Suseptibilitas}

Sampel mineral magnetik untuk masing-masing kelompok terlebih dahulu dicetak menjadi bentuk tablet. Nilai suseptibilitas magnetik sampel diukur menggunakan Bartington MS2 meter dan sensor MS2B. Pengukuran nilai suseptibilitas dilakukan pada 15 arah berbeda. Nilai suseptibilitas yang didapatkan dari alat merupakan hasil suseptibilitas berdasarkan arah pengukuran dan belum merupakan nilai suseptibilitas sampel sebenarnya. Untuk menentukan nilai suseptibilitas pada sampel digunakan software MATLAB R2013a mengikuti penelitian Palkrisman dan Budiman ( 2014)

\subsection{Penentuan Kandungan Unsur Mineral Magnetik}

Sampel pada masing-masing kelompok ditimbang sebanyak 2,0 g. Selanjutnya kandungan unsur $\mathrm{Fe}$, Ti dan $\mathrm{Si}$ pada mineral magnetik ditentukan menggunakan X-Rays Fluorescence (XRF). XRF digunakan karena sampel berbentuk butiran/serbuk dan alat ini tidak merusak komposisi sampel.

\section{HASIL DAN DISKUSI}

\subsection{Penentuan Persentase Massa Pasir Besi dan Massa Mineral Magnetik Pasir Besi}

Hasil pengelompokkan pasir besi Pantai Sunur berdasarkan ukuran butir dapat dilihat pada Gambar 1. Pasir besi di Pantai Sunur didominasi oleh Kelompok II dan Kelompok III yang memiliki ukuran butir berkisar antara $0,180-0,850 \mathrm{~mm}$. Persentase massa pasir besi tertinggi teramati pada lokasi S3 untuk Kelompok II yaitu sebesar 81,5\%.

Hasil pengukuran persentase massa kandungan mineral magnetik pasir besi Pantai Sunur pada masing-masing kelompok dapat dilihat pada Gambar 2. Persentase massa kandungan mineral magnetik rata-rata meningkat terhadap penurunan ukuran butir. Persentase massa kandungan mineral magnetik rata-rata tertinggi yaitu berkisar antara 90,7 - 93,5\% untuk mineral magnetik Kelompok V (-100 Mesh). Ansori (2013) pada penelitian pasir besi Pantai Selatan Kabupaten Kebumen mendapatkan bahwa persentase massa kandungan mineral magnetik tertinggi yaitu 81,47 \% untuk mineral magnetik dengan ukuran butir (-120 Mesh). Dengan demikian, persentase kandungan mineral magnetik Kelompok V di Pantai Sunur lebih besar dari yang didapatkan oleh Ansori (2013).

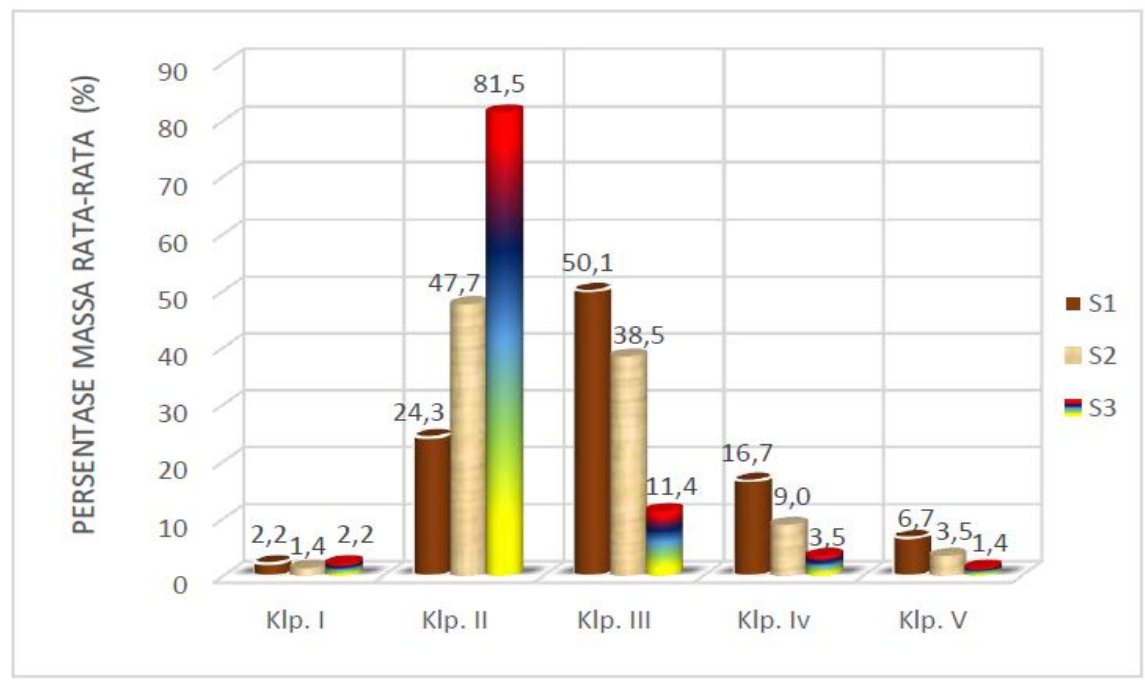

Gambar 1 Grafik persentase massa pasir besi Pantai Sunur 


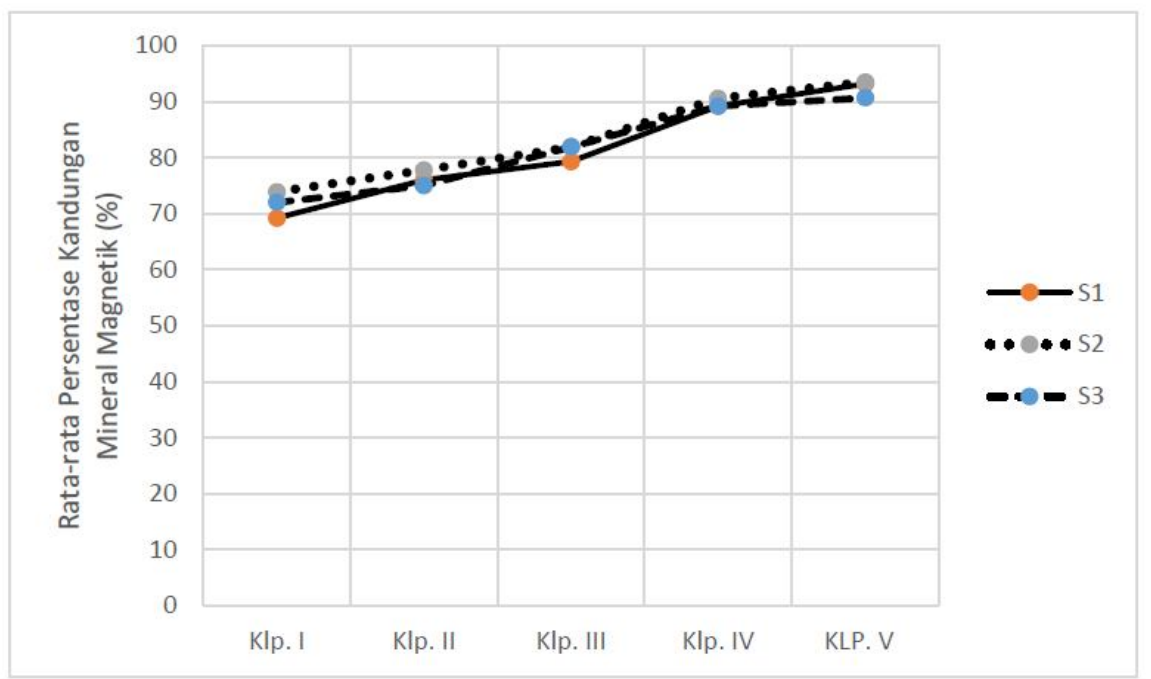

Gambar 2 Grafik persentase massa kandungan mineral magnetik pasir besi Pantai Sunur

\subsection{Hubungan Ukuran Butir Terhadap Nilai Suseptibilitas}

Hasil pengukuran nilai suseptibilitas mineral magnetik pasir besi Pantai Sunur berdasarkan kelompok ukuran butir dapat dilihat pada Gambar 3. Nilai suseptibilitas meningkat terhadap penurunan ukuran butir mineral magnetik. Hal ini dikarenakan semakin besar ukuran butir, maka semakin tinggi mineral pengotor yang berikatan. Mineral pengotor adalah mineral yang bersifat non-magnetik yang terkandung pada mineral magnetik. Ansori, dkk. (2011) mengatakan bahwa mineral magnetit dapat berupa magnetit ikat yang berikatan pada mineral mafik seperti olivin, piroksin dan hornblende. Mineral mafik termasuk mineral pengotor walaupun bersifat magnetik. Mineral magnetik utama memiliki nilai suseptibilitas yang besar, sedangkan mineral pengotor walaupun bersifat magnetik memiliki nilai suseptibilitas yang kecil. Semakin besar ukuran butir, maka semakin besar mineral pengotornya yang menyebabkan nilai suseptibilitas semakin kecil.

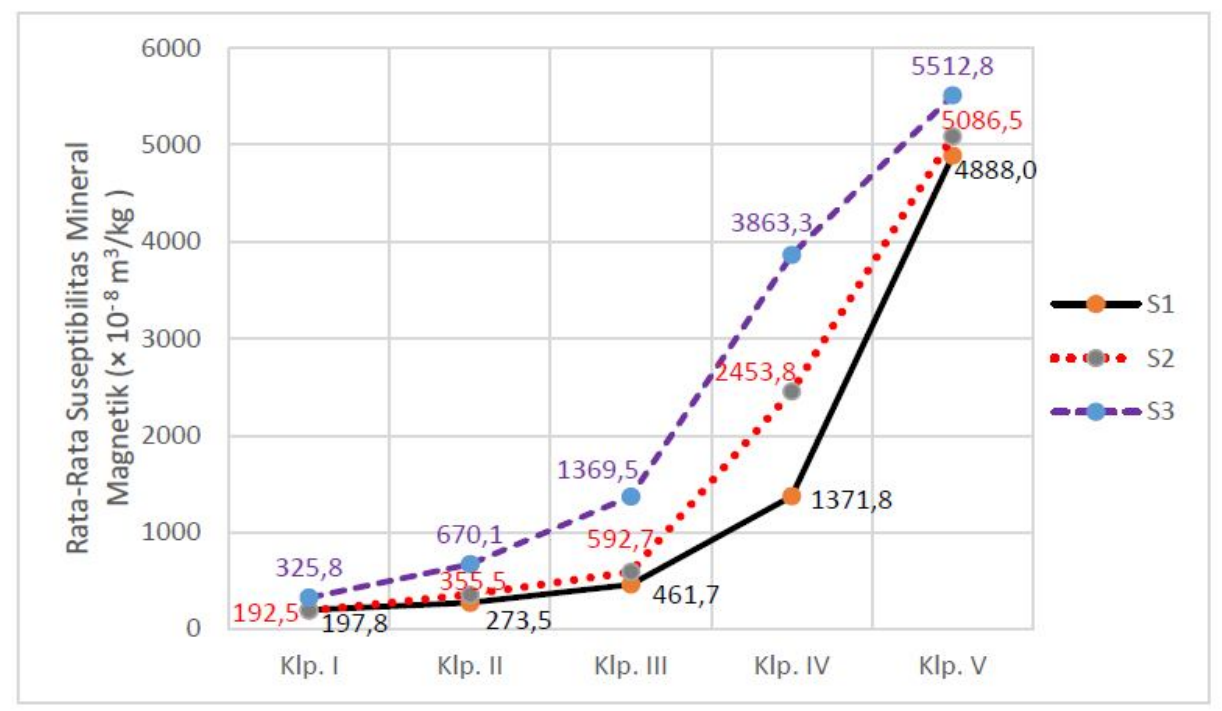

Gambar 3 Hubungan ukuran butir terhadap nilai suseptibilitas

\subsection{Hubungan Ukuran Butir Terhadap Kandungan Unsur Mineral Magnetik}

Kandungan unsur mineral magnetik ditentukan hanya pada lokasi S3 karna sampel ini memiliki nilai suseptibilitas terbesar dibandingkan lokasi lainnya. Dari hasil pengukuran diperoleh bahwa mineral magnetik terdiri dari unsur $\mathrm{Mg}, \mathrm{Al}, \mathrm{Si}, \mathrm{P}, \mathrm{K}, \mathrm{Ca}, \mathrm{Ti}, \mathrm{Fe}, \mathrm{Mn}, \mathrm{Eu}, \mathrm{V}$ dan $\mathrm{Ag}$ serta unsur-unsur lain dengan konsentrasi yang kecil. Untuk melihat hubungan ukuran butir 
terhadap kandungan unsur mineral magnetik, digunakan nilai konsentrasi $\mathrm{Fe}$, Ti dan $\mathrm{Si}$ pada setiap kelompok ukuran butir. Unsur $\mathrm{Fe}$ dan $\mathrm{Ti}$ merupakan mineral bersifat magnetik, sedangkan unsur Si merupakan mineral bersifat non-magnetik. Hubungan ukuran butir terhadap konsentrasi unsur tersebut dapat dilihat pada Gambar 4. Semakin halus ukuran butir mineral magnetik, maka konsentrasi unsur Fe dan Ti mengalami kenaikan sedangkan konsentrasi unsur $\mathrm{Si}$ mengalami penurunan. Pada mineral magnetik Kelompok V didapatkan konsentrasi unsur Fe dan Ti tertinggi yaitu sebesar 42,9\% dan 6,2 \%, sedangkan konsentrasi unsur Si terendah yaitu $34,5 \%$. Hasil konsentrasi unsur Fe didapatkan lebih kecil dibandingkan dengan penelitian yang dilakukan oleh Ansori (2013). Konsentrasi unsur Fe tertinggi yang didapatkan oleh Ansori (2013) yaitu sebesar 60,72\% pada ukuran butir (-120 Mesh).

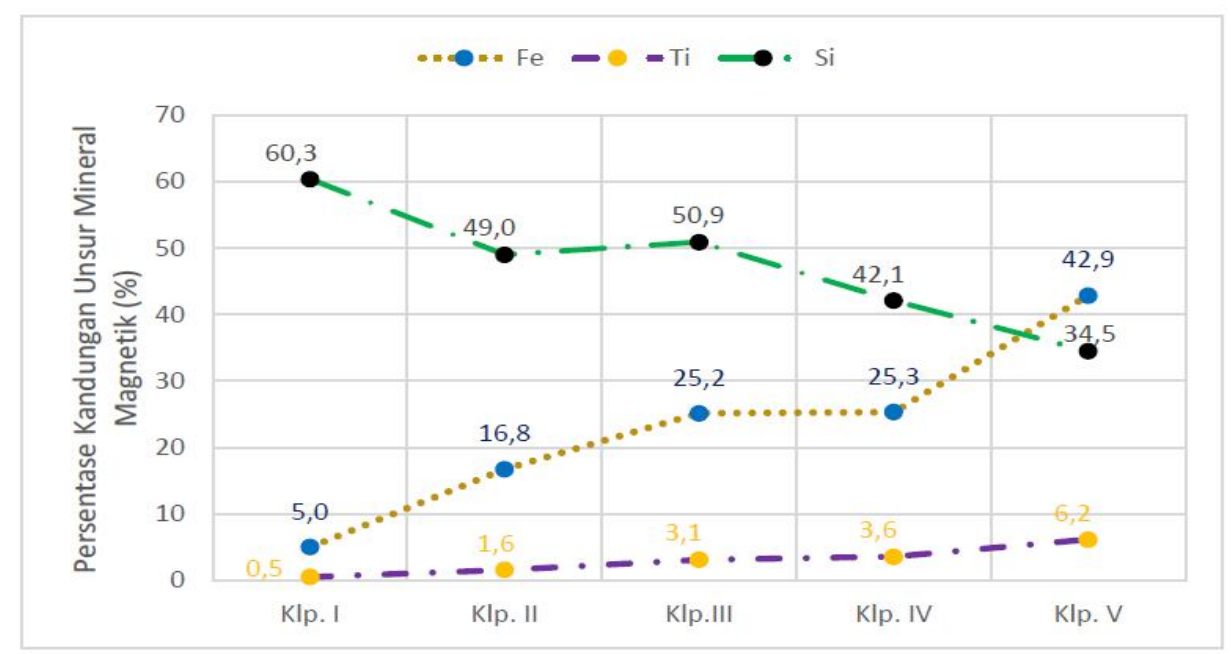

Gambar 4 Hubungan ukuran butir terhadap nilai suseptibilitas

\section{KESIMPULAN}

Penelitian ini menunjukkan bahwa ukuran butir pasir besi di Pantai Sunur Kabupaten Padang Pariaman didominasi oleh Kelompok II dan Kelompok III atau ukuran butir antara $0,180-0,850 \mathrm{~mm}$. Persentase massa kandungan mineral magnetik tertinggi berkisar antara 90,7 - 93,5\% dan terdapat pada pasir besi dengan ukuran butir kecil dari 0,150 mm. Nilai suseptibilitas meningkat terhadap penurunan ukuran butir mineral magnetik pasir besi Pantai Sunur. Nilai suseptibilitas rata-rata tertinggi dimiliki oleh mineral magnetik Kelompok V yaitu antara 4888,0 - 5512,8 $\times 10^{-8} \mathrm{~m}^{3} / \mathrm{kg}$. Hal ini disebabkan oleh peningkatan mineral magnetik seperti unsur Fe dan Ti terhadap penurunan ukuran butir mineral magnetik pasir besi Pantai Sunur dan sebaliknya untuk konsentrasi unsur Si. Mineral magnetik Kelompok V memiliki konsentrasi unsur Fe dan Ti tertinggi dan unsur Si terendah berturut-turut yaitu 42,9 \% dan 6,2 $\%$ dan $34,5 \%$. Tingginya kandungan unsur mineral magnetik dan nilai suseptibilitas pasir besi di Pantai Sunur mengindikasikan bahwa pasir besi di kawasan ini memiliki potensi untuk diaplikasikan dalam bidang magnetik seperti pembuatan besi baja dan magnet permanen.

\section{DAFTAR PUSTAKA}

Ansori, C., Sudarsono, Saifudin, Distribusi Mineralogi Pasir Besi pada Jalur Pantai Selatan Kebumen Kutoarjo, Buletin Sumber Daya Geologi 6, hal. 81-96 (2011)

Ansori, C., Jurnal Teknologi Mineral dan Batubara 9, 145-156 (2013).

Direktorat Inventarisasi Sumberdaya Mineral, "Pedoman Teknik Eksplorasi Pasir Besi”,Laporan Survey Tinjau Pusat Sumber Daya Geologi. Jakarta, 1-10 (2005).

Jalil, Z., Sari.N.E., Handoko, E., Indonesia journal of applied physics 4, 110 (2014).

Mufit, F., Fadhillah., Amir, H., Bijaksana, S., Jurnal Geofisika 1, $2-5$ (2006).

Mufit, F., Amir, H., Fadhilah, Bijaksana, S., "Kaitan Sifat Magnetik Dengan Tingkat Kehitaman (darkness) Pasir Besi di Pantai Masang Sumatera Barat”, EKSAKTA XIV Hasil Hibah Pekerti DIKTI 2, hal. 70-75 (2013).

Palkrisman dan Budiman, A., Jurnal Fisika Unand 3, 242-248 (2014). 
Sunaryo dan Widiawidura, W., "Metode Pembelajaran Bahan Magnet dan Identifikasi Kandungan Senyawa Pasir Alam Menggunakan Prinsip Dasar Fisika", Buletin Cakrawala Pendidikan FMIPA Universitas Negeri Jakarta, No.1 Th XXIX, 2010) hal. 67-79.

Yulianto, A., Bijaksana, S., Loeksmanto, W., Kurnia, D., Indonesian Journal of Material Science5, 51-54 (2003).

Yulianto, A., Aji, M.P., Idayanti, N., "Fabrikasi MnZn-Ferit dari Bahan Alam Pasir Besi Serta Aplikasinya Untuk Core Induktor, Prosiding Pertemuan Ilmiah XXIV HFI Jateng dan DIY” (HFI, Semarang, 2010) hal. 128-133.

Zulfalina dan Manaf, A., Indonesian Journal of Material Science 5, 46-50 (2004). 